\title{
BALD EAGLE AT WEITZEL LAKE, SASKATCHEWAN
}

Photos by Frank A. Heidelbauer, Sioux Falls, South Dakota

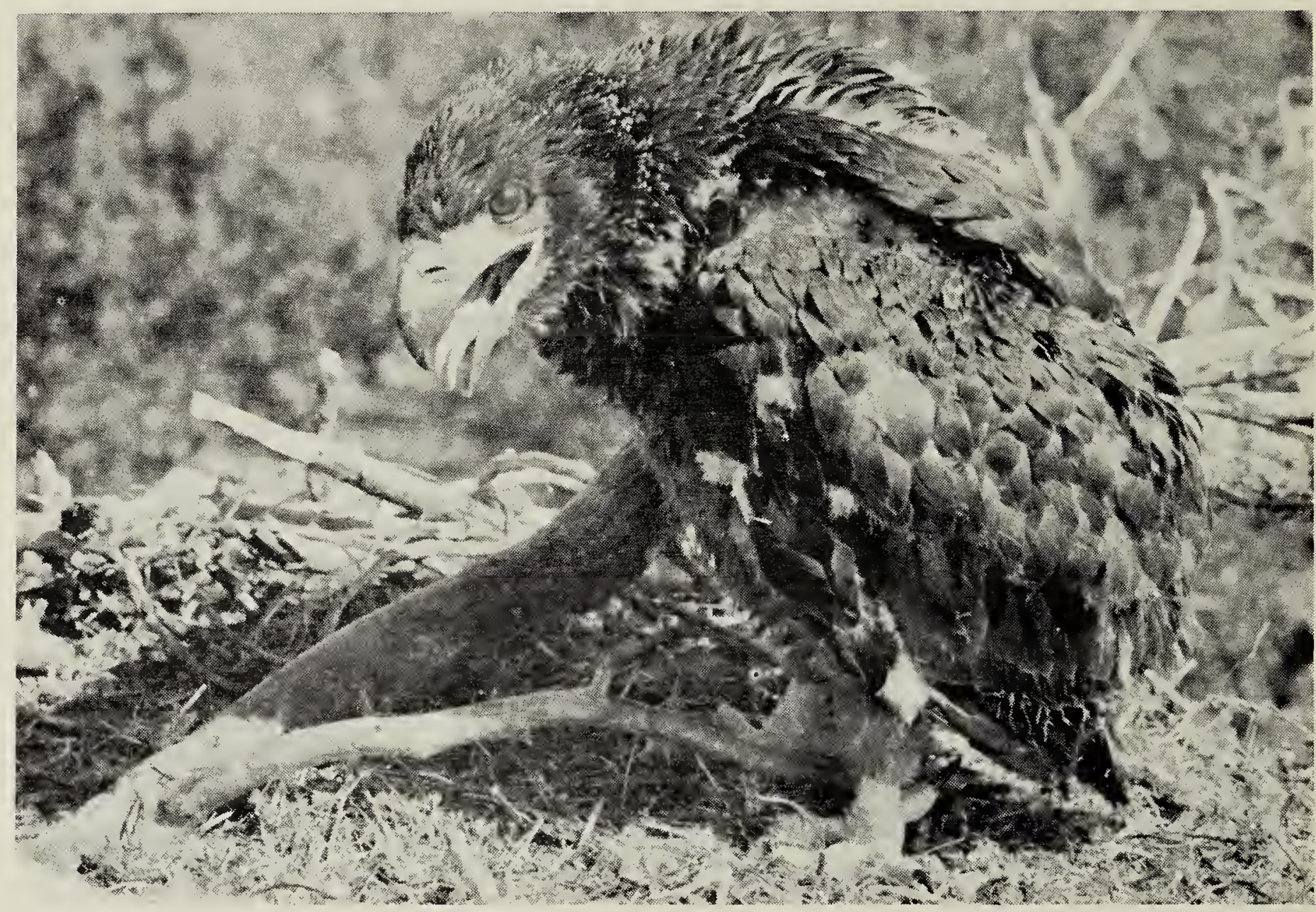

Juvenile eagle in nest, Weitzel Lake (just north of Cree Lake), July, 1962. Note tufts of down still attached to feathers on back of neck and elsewhere.

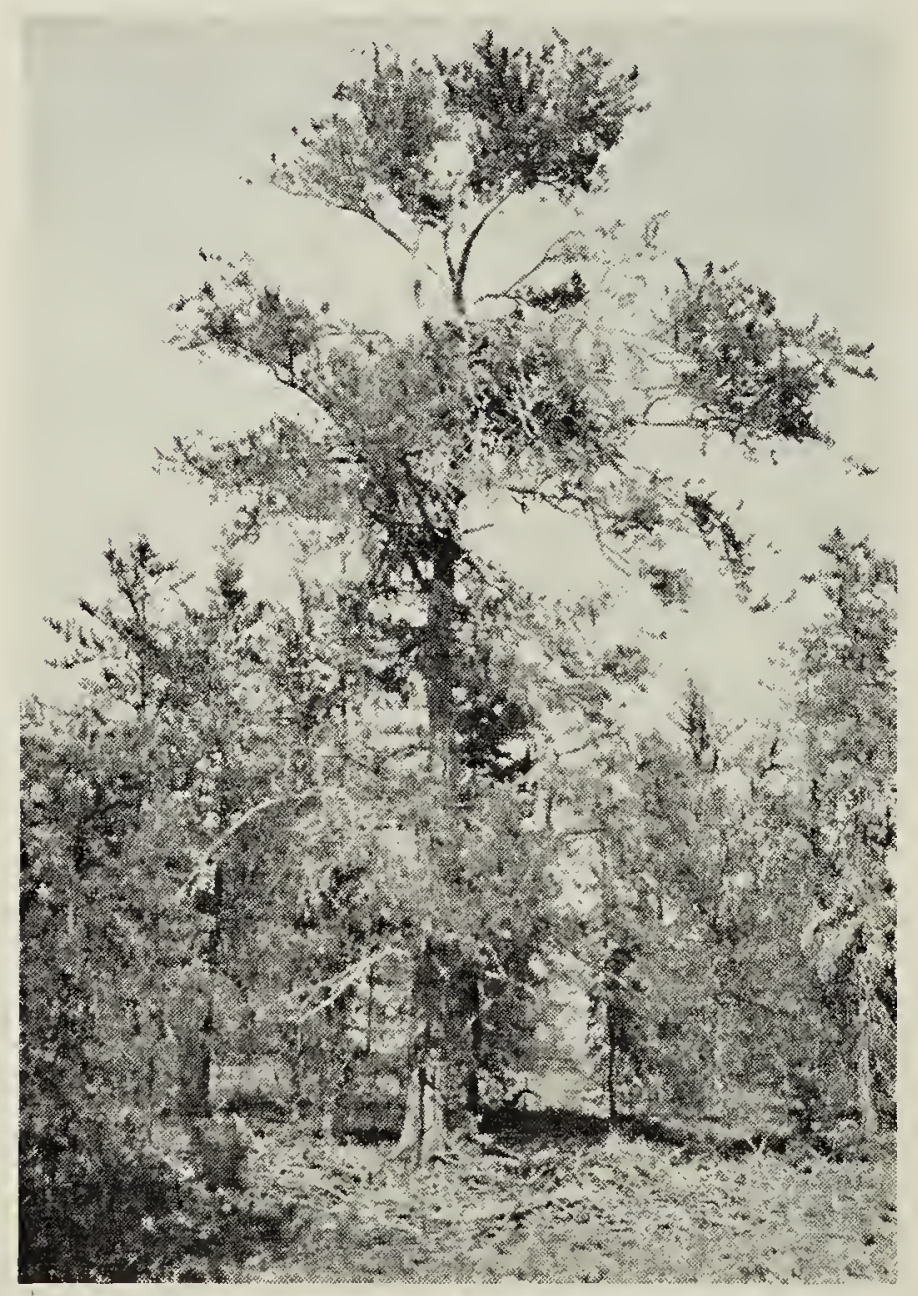

Nest in live jack pine. Note the dead branches at the base of the tree, presumably fallen or misplaced nesting material.

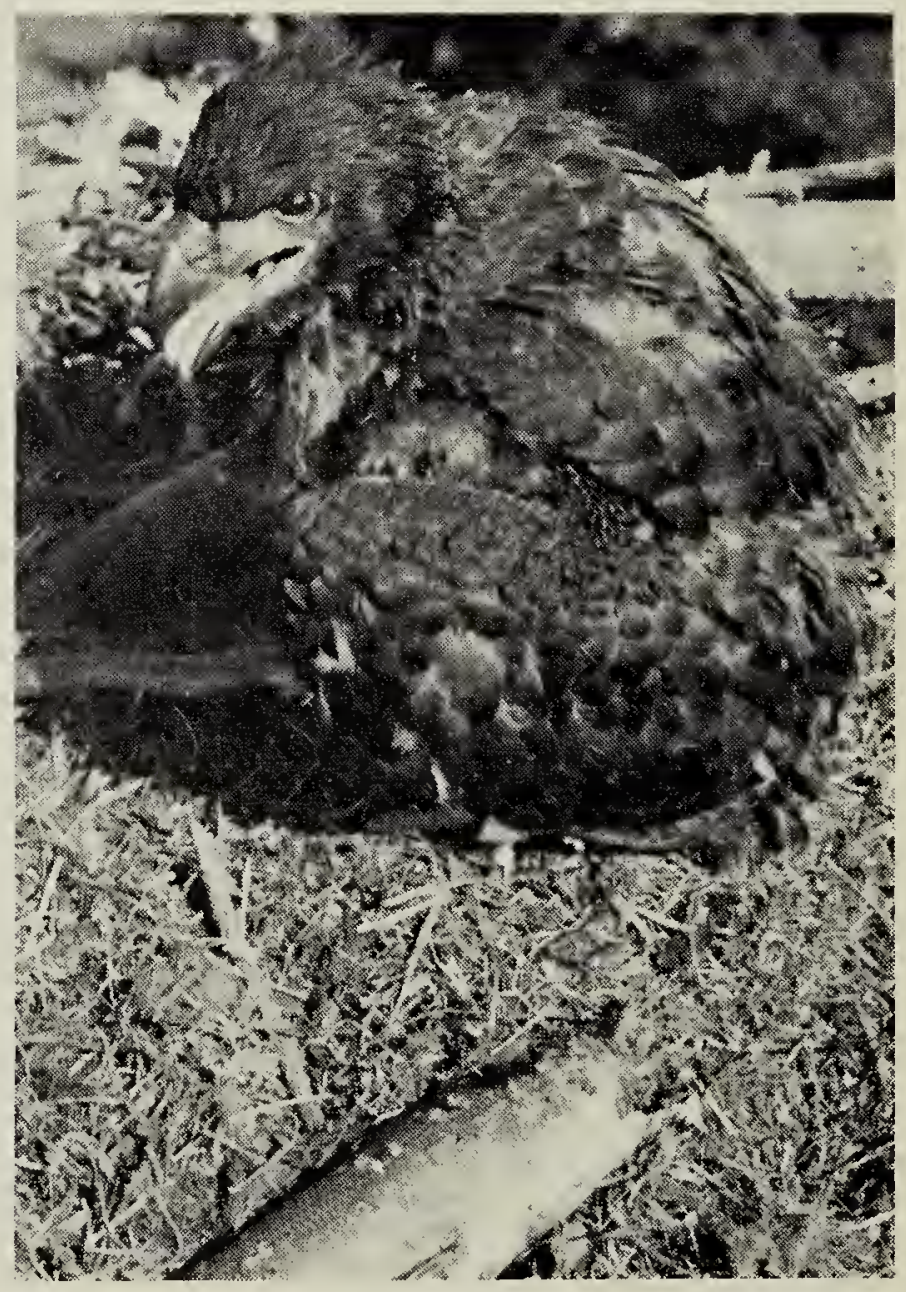

Juvenile eagle and fresh fish. Note the compacted nature and the finer materials of the nest floor. 